\title{
Recurrent hematometra with endometriosis in an adolescent girl: a case report
}

\author{
Sarita Agrawal, Rajshree Sahu*, Pushpawati Thakur, Vinita Singh, Pawan B. Chandramohan
}

Department of Obstetrics and Gynecology, All India Institute of Medical Sciences, Raipur, Chhattisgarh, India

Received: 18 August 2019

Revised: 19 September 2019

Accepted: 09 October 2019

\section{*Correspondence: \\ Dr. Rajshree Sahu, \\ E-mail: rjsahu.88@gmail.com}

Copyright: () the author(s), publisher and licensee Medip Academy. This is an open-access article distributed under the terms of the Creative Commons Attribution Non-Commercial License, which permits unrestricted non-commercial use, distribution, and reproduction in any medium, provided the original work is properly cited.

\begin{abstract}
Hematometra is a collection or retention of blood in the uterine cavity. This condition is most commonly associated with congenital uterine anomalies that result from abnormal formation, fusion or resorption of Mullerian ducts during fetal life or may be due to prior surgical procedures, causing an obstruction of the genitourinary outflow tract. We report an unusual case of hematometra with endometriosis secondary to cervical stenosis. This is a rare and important case report due to the complexity of diagnosis as cervical stenosis was not presented as primary amenorrhoea as its usual presentation. This case was successfully managed by Hysteroscopic cervical dilatation under USG guidance followed by transcervical insertion of a catheter to prevent recurrent stenosis.
\end{abstract}

Keywords: Amenorrhoea, Cervical stenosis, Endometriosis, Hemetometra, Mullerian duct, Uterine anomaly

\section{INTRODUCTION}

Cervical Stenosis is an anomalous narrowing or obstruction of any part or entire cervical canal. It may be congenital or acquired. Acquired variety usually follows cervical trauma or prior surgical procedures. Congenital uterine anomalies are due to either abnormal formation, fusion or resorption of Müllerian ducts during fetal life. Congenital cervical atresia/ stenosis is a relatively rare Mullerian duct anomaly of the female reproductive tract. We have various classification systems for congenital cervical atresia. They are the American Fertility Society classification (now the American Society of Reproductive Medicine); the Embryological-clinical classification system of genito-urinary malformations; the 'Vagina, Cervix, Uterus, Adnexa-associated Malformations' system; and the new European Society of Human Reproduction and Embryology/European Society for Gynaecological endoscopy classification system developed by the CONUTA working group. ${ }^{1}$ These classifications have limitations in terms of effective categorization of anomalies, simplicity, and clinical application. It comes under Type I (b) according to American Fertility Society Classification and Type C4 according to ESHRE Classification of Female Genital Tract Anomalies. We can classify cervical stenosis into 4 types as per location of stenosis (Table 1).

Table 1: Type and location of cervical stenosis. ${ }^{2}$

\begin{tabular}{|ll|}
\hline Type & Location of cervical stenosis \\
\hline Type 1 & stenosis of the external os \\
\hline Type 2 & $\begin{array}{l}\text { stenosis of the distal third of the cervical } \\
\text { canal and internal os }\end{array}$ \\
\hline Type 3 & stenosis of the internal os \\
\hline Type 4 & $\begin{array}{l}\text { combined stenosis of the external and } \\
\text { internal os }\end{array}$ \\
\hline
\end{tabular}

Usual manifestation of congenital cervical stenosis is primary amenorrhoea with cyclical lower abdominal pain and pelvic pressure, collection or retention of blood in the uterus (Haemetometra), urinary frequency and retention. ${ }^{3}$ 
The management of women with congenital cervical stenosis remains controversial. It may require medical therapy, surgical management or both. Generally, the more extensive the stenosis is, the more likely that it will need to be resolved surgically rather than medically. Cervical stenosis is challenging to gynecologists in that it presents an additional complication when performing procedures that require cervical dilation and/or access to the endometrial cavity, including hysteroscopy.

\section{CASE REPORT}

A 15 years old girl, presented with complaints of scanty flow during menses (for 1-2 days) with delayed cycles at interval of 2-3 months, severe dysmenorrhoea and persistent lower abdominal discomfort. She was also having pain in lower abdomen, which was cyclical, spasmodic, radiating to back and thigh, with increasing severity and present even without menstrual flow. She attained menarche at 14 years of age. Past and family history was not significant. Nothing significant present on general examination. Secondary Sexual Characters were well developed as per age. On abdominal examination, Suprapubic fullness and tenderness was present on hypogastrium and right iliac region. On per rectal examination, a Lump 12 weeks size felt anteriorly (firm, slightly tender, mobile), another lump $\sim 6 \times 4 \mathrm{~cm}$ (cystic, tender, not mobile) felt on right side, rectal mucosa free. USG abdomen was suggestive of enlarged uterus $(10 \times 5.8 \times 4.6 \mathrm{~cm})$ with fluid in endometrial cavity, right adnexal mass of $9.4 \times 5.1 \times 4.5 \mathrm{~cm}$ with heterogenous echogenicity present, Rest normal. Diagnosis of Haematometra with right Endometrioma made. she was planned for lap cystectomy and drainage of hematometra. Laproscopic findings are enlarged uterus $\sim 12$ weeks size, Right endometriotic cyst $\sim 8 \times 6 \mathrm{~cm}$, adhesions present between Tubo-ovarian mass and pelvic side wall, left tube and ovary found normal. Laproscopic right ovarian cystectomy with adhesiolysis performed. Cervical dilatation with Hegar's dilator No 4 was performed with difficulty under lap vision, larger dilators could not be negotiated. Around $100 \mathrm{ml}$ of altered brown coloured blood drained. Her next 2 menstrual cycles were normal. Then she had amenorrhoea for 2 months and admitted in emergency with complaints of severe lower abdominal pain. On ultrasonography large endometrial collection with internal echoes suggestive of Haematometra $(8 \times 5.8 \times 4 \mathrm{~cm})$ found. MRI Pelvis done suggestive of Bulky Uterus with fluid collection $(8.2 \times 6 \times 4.5 \mathrm{~cm})$ seen within endometrial cavity likely stricture at distal endometrial cavity at the level of internal os and minimal fluid in POD. In view of recurrence of hematometra, Hysteroscopy performed (Figure 1). After almost $2 \mathrm{~cm}$ of cervical canal, resistance felt and office hysteroscope could not be introduced. Paediatric cystoscope was introduced, fibrotic tissues were cut with the scissors followed by serial cervical dilatation with Hegar's dilator. Simultaneous abdominal USG was done to avoid creation of false passage (Figure 2). Intrauterine Foley's catheter kept in situ for 6 months to prevent recurrent cervical stenosis. She is having regular menstrual cycle now and doing well.

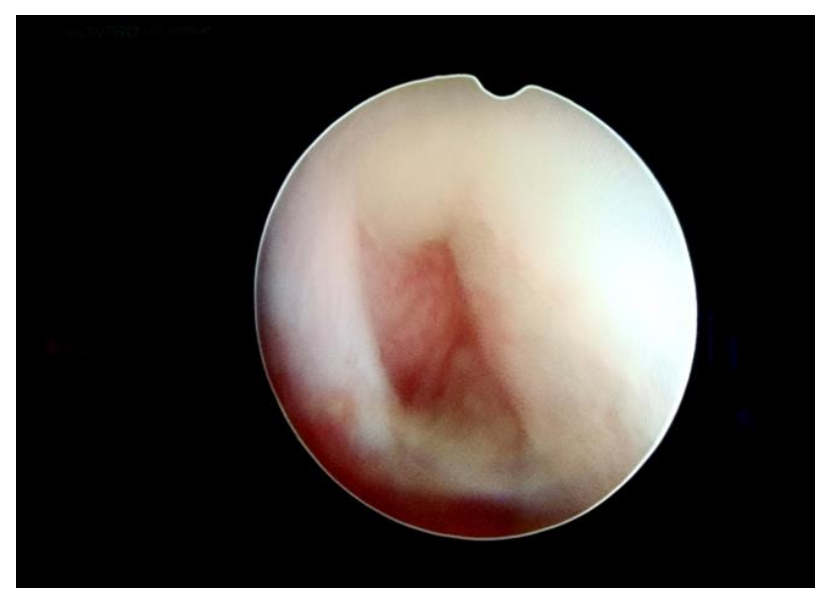

Figure 1: Hysteroscopic view showing stricture at the level of internal os.

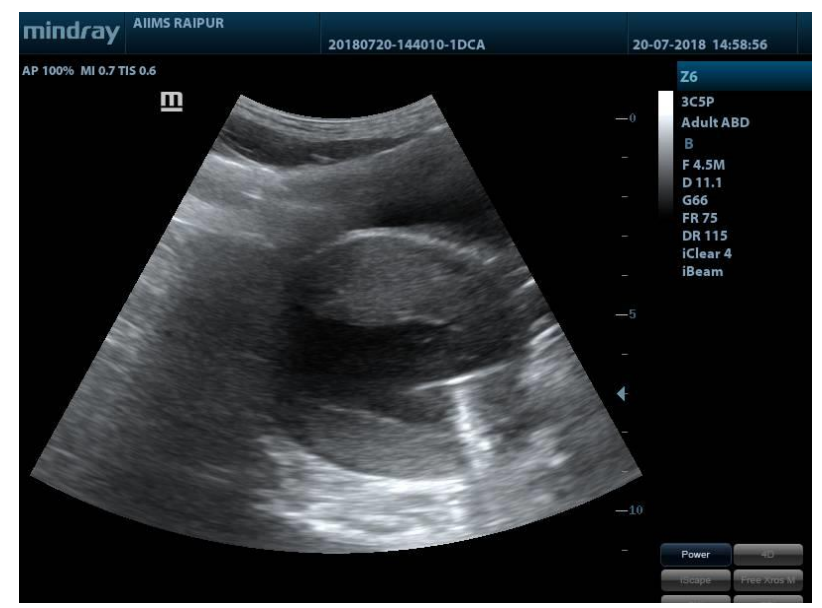

Figure 2: Transabdominal sonography showing uterus with hematometra and Cervical stricture dilatation with Hegar's dilator.

\section{DISCUSSION}

Hematometra is a condition involving the collection or retention of blood in the endometrial cavity. Most common congenital cause is Imperforate hymen. There are also reports of cases of primary hematometra due to imperforate cervix. Ultrasound and MRI are two imaging modalities that can be used in the diagnosis of hematometra. It may require medical therapy, surgical management or both. Medical methods include osmotic dilators and cervical ripening agents. Surgically cervical stenosis can be managed by using ultrasound guidance during cervical dilation or hysteroscopic methods include scissors, forceps, bipolar electrodes, resectoscopes and hysteroscopic morcellators. ${ }^{4}$ Each having varying levels of success. Unfortunately, cervical dilatation to relieve stenosis is often only a temporary success. Treatment option like transcervical insertion of a catheter after 
cervical dilatation is reported in the literature also as managed in our case.

\section{CONCLUSION}

Hysteroscopic cervical dilatation under USG guidance followed by transcervical insertion of a catheter as managed in our case can be considered as a successful treatment option for recurrent cervical stenosis.

\section{Funding: No funding sources}

Conflict of interest: None declared

Ethical approval: Not required

\section{REFERENCES}

1. Xie Z, Zhang X, Liu J, Zhang N, Xiao H, Liu Y, et al. Clinical characteristics of congenital cervical atresia based on anatomy and ultrasound: a retrospective study of 32 cases. Eu J Med Res. 2014;19(1):10.
2. Bettocchi S, Bramante S, Bifulco G, Spinelli M, Ceci $\mathrm{O}$, Fascilla FD, et al. Challenging the cervix: strategies to overcome the anatomic impediments to hysteroscopy: analysis of 31,052 office hysteroscopies. Fertil Steril. 2016;105(5):e16-7.

3. Rezai S, Lieberman D, Caton K, Semple S, Henderson CE. Hematometra and hematocolpos, secondary to cervical canal occlusion, a case report and review of literature. Obstet GynecolInt J. 2017;6(3):00208.

4. Skopec GS. A review of medical and surgical techniques for overcoming cervical stenosis. Proc Obstet Gynecol. 2018;8(1):7.

Cite this article as: Agrawal S, Sahu R, Thakur P, Singh V, Chandramohan PB. Recurrent hematometra with endometriosis in an adolescent girl: a case report. Int J Reprod Contracept Obstet Gynecol 2019;8:4567-9. 